\title{
Mi azaroso camino hacia la historia andina
}

\section{My unsteady road towards Andean history}

\author{
NICOLÁS SÁNCHEZ-ALBORNOZ
}

University of New York

nsalbornoz@gmail.com

\section{RESUMEN}

La siguiente nota autobiográfica del reconocido historiador Nicolás SánchezAlbornoz ilustra cómo las distintas vicisitudes de la vida lo llevaron al campo de la historia andina. Con la excusa de la presentación de libro Trabajo y migración indígenas en los Andes coloniales, esta mirada al pasado invita a replantear la vocación del historiador, pues la especialización temática no siempre se deberá a genuinos intereses personales o académicos, sino a distintas circunstancias politicas, geográficas y temporales.

Palabras clave: Sánchez-Albornoz, Historia andina, Historiador, Vocación

ABSTRACT

The following autobiographic note of the renowned historian Nicolás SanchezAlbornoz illustrates how life's different vicissitudes carried him to the field of Andean history. In virtue of his book Trabajo y migración indígenas en los Andes coloniales' presentation, this recount of the past invites to rethink the historian vocation. It tells us that the specialization pursued will not always be due to genuine personal or academic interests, but to different political, geographical, and temporal circumstances.

Keywords: Sánchez-Albornoz, Andean History, Historian, Vocation 
Con motivo de la publicación reciente de mi libro Trabajo y migración indígenas en los Andes coloniales, el Instituto de Estudios Peruanos de Lima y el Banco Central de Reserva del Perú, atentos a la preceptiva sanitaria vigente, organizaron la presentación de la obra de forma no presencial. Para mi intervención previa a la de los comentaristas previstos, se me ocurrió que no estarían de más algunas reflexiones propias sobre cómo desemboqué en la historia andina. Varios libros y una profusión de artículos certifican mi larga, pero no exclusiva, frecuentación de esa parcela de la historia americana. Ningún antecedente personal, ni mi formación académica, pronosticaban semejante deriva. Aquí repito -y amplío- algunos comentarios vertidos en mi intervención virtual.

La órbita en la que se desenvuelve cada historiador y la proximidad a las fuentes de información supeditan el horizonte y confina a los estudiosos andinos a su entorno, próximo o pretérito. No faltan, sin embargo, los extranjeros, principalmente europeos y norteamericanos, que escrutan la región de por vida. Su vocación arranca, por lo general, del momento en el que tuvieron que elegir tema para su tesis doctoral. Coronado el requisito académico, su carrera ulterior se aferró al terreno en el que adquirieron competencia y por el que desarrollaron cierto vínculo afectivo.

Mi caso no se ajusta a la alternativa expuesta. La predisposición por los Andes no se vislumbró en mí por ninguna parte. El azar sembró, más bien, de escollos y de titubeos el recorrido que mis pasos fueron trazando. En los años cuarenta del siglo pasado, empecé la carrera de Historia en la Facultad de Filosofía y Letras de la entonces conocida como Universidad Central de Madrid. No me matriculé en la especialidad de Historia de América, recién improvisada y con tufo imperial. Lo hice en la de Historia General, en la que América cabía en un pañuelo. La solapa del libro sometido a comentario recuerda, a continuación, que no tardé en ser detenido entonces por mi actividad estudiantil contestataria, por fuerza clandestina. La decisión de evadirme del campo de trabajo al que un consejo de guerra injustificable confinó mi tergiversada peligrosidad, me ahorró cumplir íntegra la condena atrabiliaria impuesta. Por fortuna, la fuga terminó en Francia a salvo, aunque inauguró la friolera de veintiocho años de exilio. El paréntesis abierto no implicó, 
por fortuna, una pérdida de tiempo. Abrió mis ojos y mis sentidos a perspectivas hasta entonces ocultas. El año largo de prisión cumplido antes de fugarme - hombro con hombro con campesinos, obreros y toda suerte de rebeldes - tuvo igual virtud al descubrirme un sujeto histórico que las aulas daban de lado y que me reaparecería en diversas etapas de mi recorrido ulterior con distintas trazas.

La expatriación no concluyó en Francia o en México, naciones a las que fue a parar la mayor parte de la diáspora republicana posterior a la guerra civil. Acabé en la Argentina. En Buenos Aires me esperaban la impaciencia de mi padre, exiliado ocho años antes, amén de una universidad en la que me empeñé en reanudar los estudios interrumpidos. En la enseñanza de la facultad porteña me topé con defectos conocidos y objetados en la madrileńa. Excepciones había, sin embargo, algunas. El descubrimiento del conjunto formado por la arqueología y la antropología americanas fue una de ellas. Ambas disciplinas indagaban, cada una a su manera, el aporte histórico de los pueblos originarios del continente. Su relato no dependía, por fortuna, de la retahíla de minucias políticas, tan habitual en la narración histórica convencional. Para empaparme de aquel remoto pasado, no me limité a asistir a conferencias, compulsar libros y visitar museos. La presencia en el claustro de la facultad de un especialista en el itinerario seguido a escala mundial por los pueblos cazadores y recolectores, Oswald Menghin, refugiado en la Argentina por haber colaborado con el régimen nazi como rector de la Universidad de Viena, me descubrió la posibilidad de prescindir de mediaciones. Varias vacaciones veraniegas dediqué entonces a recorrer por mi cuenta, mochila al hombro, varios tramos orientales de los Andes patagónicos en persecución del legado rupestre de sus pobladores primigenios. El relevamiento de pictografías suponía una actividad al alcance de un estudiante de recursos escasos e inexperto aún en las artes pertinentes. Revistas especializadas acogieron la novedad que mis fotografías y apuntes revelaban. Ganado de este modo cierto crédito, emprendí, también por mi cuenta, una prospección fructífera de los concheros de Tierra de Fuego en busca de materiales líticos y óseos dejados en su día atrás por los canoeros yaganes. Lo recogido se encuentra depositado hoy en 
el Museo Etnográfico de la Universidad de Buenos Aires y en el Museo de América de Madrid. Exploraciones y publicaciones espolearon mi fascinación por el pasado indígena del extremo sur americano. La atracción no llegó empero a traducirse en ocupación profesional. Un giro, menos áspero que el sufrido un lustro antes, reavivó mi gusto por la historia europea, sin llegar a apagar la curiosidad despertada por otros mundos.

Recién terminada la carrera en la Universidad de Buenos Aires, se me abrió, por cierto, la oportunidad irrecusable de explicar historia contemporánea en el nivel secundario. Falto el Liceo Francés de Buenos Aires, incidentalmente, de un profesor de plantilla capaz de exponer a los alumnos la historia de Francia y europea en francés, su dirección me propuso enseñar esa asignatura en los últimos cursos. Tenía título habilitante y un conocimiento cabal del idioma por haber cursado en Francia buena parte del bachillerato. En un par de años, acumulé una experiencia pedagógica que me sirvió poco después, con motivo de la profunda reorganización de la universidad argentina, para recibir ofertas de trabajo o para ganar concursos convocados para cubrir plazas docentes. En varias universidades del país enseñé entonces la historia moderna y contemporánea, que me retrotraía en parte a la España ausente, pero no arrinconada en mi interior. El proverbial tesón de mi padre, exiliado y medievalista, tampoco hubiera permitido semejante distanciamiento.

Un golpe de fortuna más reforzó pronto mi reencuentro intelectual con mi país de origen y con su historia reciente. La Fundación Rockefeller lanzó a comienzos de los años sesenta un programa destinado a que jóvenes profesores universitarios latinoamericanos de diversas disciplinas gozaran de la oportunidad de ampliar estudios en el extranjero. El propósito perseguido era elevar el nivel académico general de la zona, plan por el estilo, aunque en mayor escala, del que la Junta de Ampliación de Estudios había lanzado a principios de siglo para Espańa. Dentro de ese programa, la Fundación me concedió una beca de estudio e investigación para su disfrute a mi elección en un centro superior de los Estados Unidos o de Europa. Sopesadas las alternativas disponibles en mi caso —Chicago o París_, la primera a la sombra de Earl Hamilton, cuya contribución a la historia de los precios españoles en la Edad Moderna 
me había fascinado, decidí, por la amplitud de miras augurada y por resultarme familiar el idioma, por acudir a la École de Hautes Études en Sciences Sociales de París, dirigida entonces por el renombrado historiador Fernand Braudel. Esta escuela de posgrado y activo centro de investigación promovía una ciencia histórica eminentemente social, en franca ruptura con sesgos inveterados a los que descalificaba como histoire évènementielle. En esta escuela, asistí al seminario de amplios contornos dirigido por el propio Braudel, también a aquel en el que Pierre Vilar iluminaba la historia moderna y contemporánea de España y al de demografía histórica a cargo de Jean Meuvret. De los tres, saqué enseñanzas detectables en mis investigaciones y publicaciones posteriores. A los tres brindo aquí un tardío homenaje.

En París y más adelante en Londres, la misma beca me ofreció amplia oportunidad para estrenarme en la consulta de fondos documentales en gran escala. Fascinado en ese momento crítico por la historia económica contemporánea de España, cimiento de su historia social, los archivos españoles me estaban, sin embargo, cerrados por mi condición de exiliado. La consulta de los informes comerciales remitidos a sus respectivos países por los cónsules franceses y británicos acreditados en España en el siglo XIX y la consulta de cierta prensa española disponible afuera salvaron en gran parte el obstáculo que se interponía en mi camino. Las series formadas por estos escritos oficiales me proporcionaron una información supletoria. Siempre he tenido a gala, vanagloria de desterrado, de haber burlado vetos y de haber podido aportar novedades de cierta entidad al conocimiento del pasado de mi país, pese a no haber podido poner los pies en sus archivos, ni siquiera más tarde.

De regreso a la Argentina, me urgió, naturalmente, dar a conocer algunas conclusiones sacadas de la consulta de la documentación recogida por mí afuera, en particular combinando crisis de subsistencias y efectos demográficos. La labor iniciada coincidió con mi nombramiento como director del Instituto de Investigaciones Históricas de la Universidad del Litoral, en la que enseñaba desde hacía algunos años. El Instituto tenía asignada, entre otras funciones, estimular y adiestrar a los alumnos avanzados en la investigación para que su actividad profesional futura 
no quedara reducida a una exposición docente rutinaria. Mi nueva responsabilidad inauguró para siempre la bifurcación geográfica de mi quehacer histórico. Desde entonces, me enfrenté y alterné cuestiones tan diversas como la historia de la España contemporánea con la de los Andes coloniales. Si lugares y tiempos diferían, ambas materias compartían, sin embargo, la sociedad como objeto central de estudio y la cuantificación como sustento informativo.

Cuando me hice cargo del Instituto de Historia, el equivalente de Antropología había sondeado ya qué oportunidades ofrecía un valle cordillerano de la provincia argentina de Catamarca para su estudio. El de Santa María lucía una estirpe indígena abundante, al modo del resto del norte del país. Partidarios del trabajo multidisciplinar, antropólogos y arqueólogos propusieron ceder la dimensión histórica del proyecto a sus colegas de Historia. Visitado el lugar, conocida su gente y cerciorados de la disponibilidad de fuentes primarias, la colaboración fue aceptada. La microfilmación de su archivo parroquial, cuyos orígenes databan del período colonial, gozó de prioridad. Copiar ese registro singular contribuía a preservarlo y a ahorrar, además, desplazamientos de personal. Los alumnos pudieron trabajar así el año entero en el local del propio Instituto, sin tener que dejar de asistir a sus clases. La fuente a analizar rezumaba, por otra parte, originalidad. Estudios demográficos de ese género no se habían realizado hasta entonces en América Latina. La larga experiencia francesa en ese terreno prometía, en principio, resultados satisfactorios para el caso contemplado.

El local del Instituto llegó a quedar inundado de fichas, planillas y gráficos, de lectores y de calculadoras en el aciago momento en el que un golpe militar no se contentó con derribar al gobierno electo de la nación y ocupó todas las universidades del país, forzando a una mayoría de sus docentes a renunciar a sus cargos en protesta por el avasallamiento de las casas de estudio. Los militares daban un higo por la educación y la ciencia, de modo que no se les ocurrió rectificar o negociar. Los claustros se vaciaron, las investigaciones en curso fenecieron y los resultados obtenidos se disiparon. De brazos no me crucé durante el ocio y la frugalidad impuestos. Supe aprovecharlos para escribir, menudencias 
aparte, un par de libros que consagraron una segunda ambivalencia en mis preocupaciones históricas, es decir el cultivo simultáneo de la historia económica y de la demografía histórica. Las obras acometidas - España hace un siglo: Una economía dual e Historia de la población de América Latina - obtuvieron, una vez publicadas, una acogida amplia por la novedad que aportaban. La aceptación se tradujo en ediciones sucesivas y, en el caso del segundo libro, en actualizaciones periódicas y en traducciones a dos otros idiomas de proyección mundial. Mi refugio intelectual en el Buenos Aires de aquel tiempo ingrato se pobló de economistas y de sociólogos. Contando con mi tiempo libre y su confianza, me encomendaron la dirección de la revista Desarrollo Económico, con lo que salí ganando en familiaridad con ambas disciplinas. Al cabo de un par de años de una situación insostenible, dejé Buenos Aires para Nueva York con la pesadumbre de ver arruinados los esfuerzos propios y ajenos.

La investigación emprendida en el noroeste argentino abrió mi mente a su gente y a sus problemas, contemporáneos e históricos, y me sugirió que debiera cruzar el límite septentrional hasta el corazón de los Andes. El paso dado no tendría vuelta atrás. La ampliación de horizonte sobrevino con el conocimiento anticipado de las fuentes adecuadas. Al iniciar la investigación sobre Santa María, me propuse buscar información complementaria fuera del valle. Revolví sin demasiado éxito los archivos de los vecinos Tucumán y Salta, pero el repositorio disponible más fértil demostró ser el distante Archivo General de la Nación de Buenos Aires. Las pesquisas realizadas en él suministraron pocas menciones sobre el valle remoto y, encima, a trasmano de las rutas de comunicación más frecuentadas. La consulta del AGN desplegó, en cambio. el rico arsenal de documentación demográfica y fiscal colonial que guardaba y que sigue custodiando. Este valioso material ingresó en el archivo predecesor del actual, por transferencia de Lima a la capital porteńa de los fondos relativos a la antigua Audiencia de Charcas, cuando su territorio fue cedido, a fines del siglo XVIII, al recién creado virreinato del Río de la Plata. Algún documento hallado fue sometido a examen de los alumnos. Otros recibieron un tratamiento especial. El grueso permaneció a la espera de más visitas y de otros visitantes, que con el tiempo llegaron. 
Mi marcha a los Estados Unidos no truncó el interés despertado por la historia colonial andina. Buenas razones se dieron para que no ocurriera así. El Departamento de Historia de la NYU, donde recalé, valoró como un activo mi doble especialidad histórica. Podía atender a dos tipos de demandas de los estudiantes graduados, los aspirantes a especializarse en la Europa contemporánea o los interesados en la América Latina, en especial la meridional. Mientras enseńaba cursos relacionados con ambas especialidades, mi investigación principal estuvo inicialmente centrada en buena medida en una labor básica: la reconstrucción de las estadísticas mensuales de los precios agrícolas de la España del siglo XIX. Ellas ponían de relieve, por una parte, la oscilante evolución de la economía primordial de España y, por otro lado, los cambios de configuración del mercado nacional. A mi entender, este tipo de datos proporcionaba un acceso más elocuente a la economía, fundamentalmente agraria, que el que pudiera desprenderse por la vía institucional. La Gaceta oficial, asequible en distintas bibliotecas en el exterior, me facilitó el vuelco de esa información. Los datos y las conclusiones extraídas tardaron en ser dados a conocer. Acabaron viendo la luz más adelante en una España en trance de transformación. La elaboración y el análisis de los precios contó con la facilidad, en ahorro de tiempo y de trabajo, proporcionada por la apreciable dotación de NYU para el cálculo en gran escala y a alta velocidad. Eran los años iniciales del uso, por las ciencias sociales, de las computadoras alimentadas con tarjetas perforadas. Apliqué más adelante la experiencia recogida a los datos andinos. De la práctica, extraje además la conclusión de que los estudiantes del departamento ganarían si se adiestraban en técnicas de análisis de punta. De tanto en tanto, ofrecí cursos introductorios a la programación y al análisis electrónico de datos históricos.

Nueva York y su universidad premiaban la investigación de sus docentes, pero no disponían, ni tenía por qué haberlas en el país del norte, de fuentes históricas concernientes a mis especialidades geográficas. Su búsqueda y consulta obligaban a viajar a tierras lejanas; en mi caso, a España o a América del Sur. El primer destino me seguía cerrado y la documentación europea supletoria me había revelado ya sus 
limitaciones. El sur del continente se abría, en cambio, a una consulta llena de promesas. El fondo andino colonial del AGN de Buenos Aires, de cuya riqueza el eminente historiador mexicano Silvio Zavala había dejado amplia constancia, seguía augurando novedades.

Para poder volver a consultar este fondo, a pesar de residir en Nueva York, se juntaron, amén de mi alerta profesional, factores personales y otros. Mi padre, mis hijos y la familia de mi mujer seguían en la Argentina. Aprovechar las vacaciones escolares del hemisferio norte para pasar allí unas semanas junto a ellos, invitaba al viaje. El cambio de hemisferio permitía, además, paradas en el camino para explorar los archivos de Sucre y Lima, conocer los países sobre los que escribía y trabar o cultivar relaciones con los historiadores locales. A estos estímulos, se añadía el generoso respaldo a la investigación que brindaban habitualmente las instituciones educativas y científicas norteamericanas. La concesión de tiempo libre y de financiación procuraba plena dedicación al objetivo perseguido. De esos vaivenes veraniegos, volvía a Nueva York cargado de fotocopias o de microfilmes que me excusaban la transcripción y análisis in situ de los documentos concernientes a "las provincias de arriba» o, eventualmente, de algún otro relativo al Bajo Perú, incluido por descuido en los fardos despachados siglos antes a Buenos Aires.

De los historiadores peruanos, con los que he tenido más trato y de los que he recibido más apoyo para mis investigaciones, me complace destacar a dos: Pablo Macera y Franklin Pease. A Pablo Macera le conocí en la Argentina cuando, llevado por la curiosidad, visitó el Instituto de Historia cuando aún lo dirigía. En mis escalas en Lima, fue de visita obligada. Él dio entrada en Perú a mis estudios andinos. En 1973, acogió un trabajo mío en la serie de publicaciones de su seminario de la Universidad de San Marcos. Su modesta difusión ayudó, sin embargo, a que el Instituto de Estudios Peruanos decidiera recoger en un libro trabajos míos dispersos. A Franklin Pease me presentó nuestro común amigo el insigne antropólogo John Murra. Franklin me abrió en el acto las páginas de la revista Histórica y me animó en mis nuevos proyectos. Cruzamos cartas y seguimos viéndonos en sus frecuentes visitas a los Estados Unidos con escala, a menudo, en Nueva York o, si no, a mí paso 
por Lima. Debo mencionar además mi relación con Luis Glave Testino, instalado en Sevilla, que la proximidad ha reforzado. De los historiadores bolivianos, debo hacer mención especial de Gunnar Mendoza, bajo cuya dirección sonsaqué al archivo de Sucre.

$\mathrm{Al}$ estrenarme hace años como investigador, mi condición de expatriado me inclinó hacia la historia contemporánea de Espańa, en expresión por lo menos de protesta y de autoafirmación. La dictadura que me tenía entre ceja y ceja llegó, sin embargo, a su fin con el cese consiguiente de las restricciones que me afectaban. Al cabo de casi tres decenios, pude pisar mi país de nuevo y acudir a sus archivos. ¿Aprovecharía este vuelco de la fortuna para perseverar en el objetivo inicial? De ser así, mis incursiones americanas, desde los escarceos patagónicos hasta las migraciones andinas, pasando por la omnicomprensiva historia de la población latinoamericana, era de temer que quedaran reducidas a meras digresiones, ya innecesarias, de mi actividad principal. La respuesta a ambas preguntas es no. Resta por precisar por qué fue negativa.

Para empezar, nótese que el cambio producido en España no estimuló, por reticencias y lentitudes, la inserción de los exiliados. Su regreso quedó librado a decisión propia, sin haberles ofrecido un hueco. A la llegada a España de los primeros, hubo homenajes de carácter privado, pero faltó el reconocimiento público de su condición y de lo que el exilio significaba para el conjunto de la nación. La inmovilidad del viejo aparato del Estado sembró, por otra parte, desconfianza. Para el exiliado de larga data, su residencia y su trabajo siguieron estando prudentemente afuera, salvo tanteos. En cuanto a los archivos y a la documentación oficial, fundamentales para el trabajo del historiador, poco se progresó de momento. El principio de trasparencia tardó años en imponerse sobre el hábito de la ocultación.

En mi caso, la vuelta a España, intermitente por varios años, me permitió ampliar entonces mi círculo local de interlocutores. Los contactos me valieron para comprobar el gran esfuerzo realizado por mis colegas para elevar en poco tiempo el nivel de los estudios y de la investigación en mi especialidad. La evidencia acumulada restó, en mí, cierto grado de disposición a plantear más retos y cuestiones audaces. Es más, la historia 
española experimentó entonces un giro cronológico significativo. Incorporó a su perspectiva los tiempos presentes. Reclamó en efecto requilibrar el relato oficial vigente con las voces largamente silenciadas, abordar los temas vetados sobre los atropellos cometidos durante la guerra civil y la represión posterior y tratar del exilio en todas sus dimensiones. $\mathrm{Al}$ aproximarse al presente, el historiador se arriesgaba a ser tentado a testimoniar por deber cívico o por aceptar ciertas demandas no académicas. En mi caso, la oferta llegó a ser inexcusable: un cometido oficial de índole cultural internacional, francamente incompatible, por absorbente, con la continuidad de la investigación histórica o, ni siquiera, con la posibilidad de mantenerse al tanto de los constantes avances en el campo propio.

Mi compromiso, el retiro de la enseńanza universitaria y mi regreso definitivo a Espańa confluyeron en un mismo momento. Finalizado el encargo recibido, se me presentó un tiempo disponible para el far niente, para emprender un proyecto nuevo o para dar marcha atrás y retomar los temas de las historias de España o de los Andes aparcados temporalmente. La historia económica de Espańa cedió entonces el paso. El primero plano lo ocupó la historia social andina. Un tema común a España y América llevaba tiempo ocupando mi mente y mi pluma: las migraciones transoceánicas y las interiores a cada país. No debe pues sorprender que interpretara los desplazamientos indígenas del altiplano bajo esa óptica. En mi libro Indios y tributos en el Alto Perú, publicado también por el Instituto de Estudios Peruanos (1978), había percibido ya que una parte variable de la merma del número de tributarios de la que la secuencia de registros fiscales daba cuenta no debía responder a contracción de la población, sino a ocultación o huida documentables. Los desaparecidos resultaban, en suma, susceptibles de emerger en otro lugar. Su reaparición los convertía indefectiblemente en migrantes. Mi libro reciente aborda y cuantifica, precisamente, varios movimientos de dimensiones y direcciones diversas y por motivos distintos. Su publicación me reinserta en los Andes y ensancha, por consiguiente, el brazo más joven de la bifurcación, ya mencionada, de mis estudios históricos.

El libro ahora publicado atestigua que el tema andino ganó la última mano de un envite permanente. El libro presentado no agota la cantera 
con que cuento. En cartera guardo, en avanzado estado de elaboración, más cabos sueltos que desearía que vieran la luz, si las circunstancias y el tiempo, que se acorta, lo permitieran.

Al final de la trayectoria expuesta, cabe concluir que los escollos, titubeos y ambivalencias, enfrentados a lo largo de una vida, no han desbaratado, pero sí trazado un camino tortuoso hacia una vocación.

Fecha de recepción 4/II/2021 Fecha de aceptación 5/III/2021 